\title{
Multiplicidade e plurissignificação: o vermelho multicor de Helena Parente Cunha
}

Multiplicity and plurissignification: the multicolor red of Helena Parente Cunha

Andrea do Roccio Souto

Universidade Federal de Santa Maria

DOI: https://doi.org/10.5902/2176148537311

Resumo: Nesse estudo, a partir da proposta de leitura analítica e interpretativa de Sérgio Farina, analisa-se As doze cores do vermelho, de Helena Parente Cunha. Publicada originalmente em 1989, a obra busca desconstruir o discurso homogêneo da cultura patriarcal hegemônica, discutir questões relacionadas à mulher em nossa sociedade, repensar o caráter da produção literária feminina e construir discursos em que a mulher seja vista como sujeito.

Palavras-chave: Mulheres. Escrita. Crítica feminista. Vermelho.

Abstract: In this paper, based on Sérgio Farina's analytical and interpretative reading proposal, we analyze As doze cores do vermelho, by Helena Parente Cunha. Originally published in 1989, the book seeks to deconstruct the homogeneous discourse of the patriarchal hegemonic culture, to discuss issues related to women in our society, to rethink the female literary production and to construct discourses in which women are seen as subjects.

Keywords: Women. Writing. Feminist criticism. Red. 
Fiz de mim o que não soube,

E o que podia fazer de mim não o fiz.

o dominó que vesti era errado.

Conheceram-me logo por quem não era e não desmenti, e perdi-me.

Quando quis tirar a máscara,

Estava pegada à cara.

Quando a tirei e me vi ao espelho,

Já tinha envelhecido.

Andrea do

Álvaro de Campos

Roccio Souto

Alguns aspectos da proposta de leitura analítica e interpretativa contidos no Estatuto poético, fruto da tese de doutoramento em Teoria da Literatura do professor Sérgio Farina, são bastante rentáveis se aplicados a As doze cores do vermelho. A sistematização que Farina propõe está baseada no (re) exame de variadas abordagens textuais, visto que, para o autor, a "Teoria Literária, entidade reguladora do fenômeno literário, tem a finalidade de reexaminar, contínua e sucessivamente, seu corpus teórico-prático" (FARINA, 1986, p. 243). A proposta constitui-se de três momentos distintos: leitura do contexto (circunstâncias periféricas) ${ }^{1}$, leitura do fenotexto ${ }^{2}$ (estrutura de superfície) e leitura do genotexto ${ }^{3}$ (estrutura profunda).

Sendo a historiografia literária um dos elementos a serem abordados na leitura do contexto, cabe dizer que Helena Parente Cunha é Professora Titular de Teoria da Literatura na Faculdade de Letras da $\mathrm{UFRJ}^{4}$ - o que, de forma determinante, influi na construção de sua narrativa (ou na desconstrução do modo tradicional de narrar), contrariando, em certa medida, a ideia da Teoria Literária como entidade reguladora da literatura, tal como exposta por Farina.

1 Ou leitura indicial, em que se observam contexto, índice, a relação entre história e ficção, historiografia literária, biografia do autor, época e tendências estético-literárias, aspectos grafo-visuais do texto, como notas, ilustrações, capítulos. Além disso, aqui se estabelece o estatuto poético da historicidade, ou seja, a palavra é encarada como matéria-prima do tempo/espaço.

2 Ou leitura extensiva, em busca da produtividade de sentidos, em que figura a descrição interna da obra como processo de compreensão: assunto, foco narrativo, narrador, relações/metáforas. Nesse ponto surgem a leitura dos códigos, a visão interdisciplinar e cultural da obra, o estatuto do ritmo e da ambiguidade, além de se estabelecer a estrutura de superfície do texto, isto é, a fórmula dicotômica que encaminhará o processo de leitura.

3 Ou leitura profunda, em que o texto é percebido como produtividade e como estrutura, momento em que se estabelece seu signo-texto, em que emerge o mito/imagem arquetípica, apontando para o signo da transformação social. É nesse momento também que se estabelece o estatuto da unidade e da universalidade. 4 UFRJ: Universidade Federal do Rio de Janeiro. 
Embora escreva também poesia, as obras em narrativa da autora brasileira é que têm merecido destaque: o romance Mulher no espelho, de 1982, apesar de, paradoxalmente, ter sido alvo de duras críticas, recebeu prêmios literários de importância nacional e elogios da imprensa, além de ser traduzido para o inglês e o alemão. Aliás, contos seus integram antologias estrangeiras, o que atesta a importância de sua produção literária.

A prática de Helena Parente Cunha apropria-se de "um instrumental teórico e crítico do ponto de vista feminista" (CUNHA, 1997, p. 107), pois, como afirma Rita Schmidt,

[...] não há como ignorar o fato de que a configuração de nossa cultura e a constituição do saber no ocidente foram processos que ocorreram num contexto violento de repressão das diferenças, de exclusão das vozes ex-cêntricas, de subjugação das culturas não européias, de desvalorização do outro, de sua identidade, sua história e sua cultura. Tudo em nome de verdades objetivas, pretensamente universais que, hoje, traduzimos por racismo, imperialismo, patriarcalismo. [...] o sexismo foi um discurso construído pela cultura dominante (SCHMIDT, 1996, p. 139).

Dessa forma, a autora de As doze cores do vermelho busca desconstruir o discurso homogêneo da cultura dominante (não raro patriarcalista), com a intenção de reconstruir um canal discursivo em que a voz da mulher se faça ouvir. E nesse rastro, aspectos importantíssimos elencados por Rita Schmidt (1996), colocados como questões de fundo cultural, além da busca da identidade feminina e da construção de sua história como sujeito - elementos fragmentados tal qual um quebra-cabeças, que pode não conter todas as peças à disposição - vêm à tona através da narrativa truncada, mas lírica, de Helena Parente Cunha.

Os aspectos que Rita Schmidt (1996) levanta aparecem combinados na fórmula violência/repressão/exclusão (em todos os tempos e lugares), apontando a desvalorização de que a mulher é alvo (partindo tanto do homem quanto de si própria). Tais aspectos pontuam toda a narrativa, e já na "espécie" de introdução que precede os módulos do romance vêm fazer um alerta, ou uma preparação de leitura: 
[...] a protagonista se compõe e decompõe, enlaçada às demais personagens que a acompanham no entrançado do percurso.

[...] Fragmentos e totalidade, instantâneos e fluxos de vida. Existir é juntar pedaços que permanecem e coexistem em dimensão una e múltipla (CUNHA, 1998, p. 13).

A primeira edição do romance de que aqui nos ocupamos data de 1989. Essa foi uma década importante para as mulheres no Brasil, visto que a teorização e a crítica de uma perspectiva feminista começavam Andrea do a tomar força no meio literário, procurando resgatar e contemplar as Roccio Souto discussões dos impasses de que Rita Schmidt (1996, p. 138) nos dá notícias em suas "anotações para uma resposta possível” à problemática do 118 sujeito feminino.

Como Mulher no espelho, As doze cores do vermelho reflete esse caráter até certo ponto inovador em nossa literatura, pois levanta e apresenta subsídios para que discutamos a questão da mulher em nossa sociedade patriarcalista. Destacamos uma passagem de As doze cores que enfoca bem isso:

Ela olhará as filhas crescendo. Brinquedo e figurações. Estórias de bichos estórias de cores. E às meninas dirá os segredos do corpo e as palpitações e os nós. E calará espaços de difícil redondo. E não saberá se deve dizer o seu ardente pensar e o seu multicor sentir. [...] Não estará certa da certeza dos seus desejos. E às filhas não dirá nem dizendo nem palavra nem calasse. No rosto pesarão as curvas e as interrogações. [...] Sem se convencer da legitimidade do grito e da onda. A amiga dos olhos verdes dizendo que fazer sexo com muitos homens é uma necessidade biológica e psíquica da mulher que precisa se libertar da sujeição ancestral (CUNHA, 1998, p. 19).

Não é demais observar que sua produção se filia à estética do pós-modernismo, já que a crítica feminista, a desconstrução do discurso dominante/patriarcalista e as inquietações a respeito do fazer são marcas registradas de sua narrativa, bem como pelo tratamento que dá à linguagem, além da perspectiva pós-colonialista que perpassa os ditos espaços vazios do romance e que se reflete nas relações e representações das personagens. $\mathrm{O}$ estatuto da personagem protagonista de 
As doze cores do vermelho na relação direta (ou não) com suas filhas e amigas vai conferindo e esboçando forma/conteúdo literário gradativa e fragmentadamente, através de um

[...] processo psíquico de construção da identidade como algo conflitante e ambíguo. [...] As ambiguidades do processo de construção da identidade, porém, passando pela dialética da alteridade, abrem fendas no discurso colonial, pelas quais se infiltra a alteridade do colonizado que, desse modo, subverte a putativa supremacia colonial (SOUZA, 1996, p. 561).

Multiplicidadee plurissignificação

Há uma passagem do romance - em que a protagonista e a filha mais velha figuram - que filtra o processo de construção da personagem na relação identidade-alteridade, conforme descrito acima, apontando para avanços neste final de século/milênio, os quais, apesar de serem considerados conquistas, ainda causam certo receio às próprias mulheres, firmando a imagem feminina do mosaico-caleidoscópio proposta por Helena Parente Cunha. Na citação abaixo vemos que, em relação à mãe, a menina mais velha, do riso de vidros que se quebram, assume uma fatia maior da identidade feminina que vem sendo construída pelas mulheres:

A filha maior dizendo que a virgindade é uma convenção inventada para reprimir a mulher. Susto de outras migrações. Ela vai querer dizer à filha que se a moça casa virgem impõe respeito ao marido. Ela vai querer repetir para a filha o que ouviu de tantas vozes antes de antes e depois de depois. Mas ela nunca terá certeza. Elos e laços e nós por quê? Ela tremerá ouvindo a filha dizer que está livre da repressão sexual. Pequeno animal solto em campos de flor e vento. Infringir e ruptura e sonoramente. Desejos em precipício. [...] A filha [...] firmando o passo transbordante do lado de lá. Madrugada de seivas prematuras. Do lado de cá as grossas paredes e os compactos códigos. A menina sonora traçando itinerários sem fronteiras nem balizas (CUNHA, 1998, p. 63).

Referentemente aos aspectos grafo-visuais do texto, é imprescindível mencionarmos de que modo está configurada na página a narrativa de As doze cores do vermelho, para o que, aliás, a própria autora 
Andrea do

Roccio Souto

120

chama a atenção do leitor na advertência, intitulada "Antes de atravessar o arco-íris": "essa é uma estória de simultaneidades, em três tempos e três vozes, num tecido que se estende e se desdobra nas três colunas de cada capítulo" (CUNHA, 1998, p. 13) ou módulo. Espacializado em colunas que também remetem à fragmentação, deparamo-nos com um todo que talvez não possa ser definido como uno, senão como um mosaico caleidoscópico: o tempo, a personalidade da protagonista e a própria história ao mesmo tempo em que deslocam sentidos se esfarelando, adquirem novo sentido ao se amalgamarem.

Quanto ao estatuto poético da historicidade, isto é, quanto à palavra como matéria-prima do tempo/espaço, o discurso de As doze cores do vermelho denuncia a situação de subserviência a que está submetido o sujeito feminino e sua luta para livrar-se do jugo causado pela diferença de gênero entendida como elemento negativo. Ou, dito de outra forma, As doze cores do vermelho trata do objeto feminino em busca de sua redenção como sujeito, em um país colonizado, cujo poder é sufocantemente patriarcalista. Isso fica suficientemente claro através da metáfora da pintura/desenho que segue:

\footnotetext{
Eu não queria copiar. Cópia e reduplicação e amarrado de linha limitadamente. Eu queria desamarrar o traço e desenrolar o fio e segurar outro caminhando. Eu queria desenhar a ânfora como eu queria. A simetria no desmedir. O lado de lá é diferente do lado de cá. Nada é igual a nada. Tudo é igual a tudo. [...] Reduplicação reprodução imitação ão e ão. [...] Igual ao modelo. [...] Ângulo agudo em minha cabeça (CUNHA, 1998, p. 22).
}

No que se refere ao fenotexto, ou leitura extensiva, em busca da produtividade de sentidos, podemos dizer que a estrutura de superfície de As doze cores do vermelho aponta para dicotomias marcadas pela oposição lado de lá vs. lado de cá:

Cansada. Casada. Você está cansada do lado de cá. Mas onde a coragem? O lado de lá (CUNHA, 1998, p. 47).

Ela terá muitos medos e muitas coragens. O lado de lá e o lado de cá. Nos dois lados as cores transbordarão mais luminosas e mais sombrias. [...] Vozes farão muitos ruídos dos dois lados. Ela continuará a tentar conciliar sua pintura com os afazeres do- 
mésticos. Os quadros dela mais as fichas dos clientes do marido. As formas informes e as fôrmas conformes. [...] o lado de cá é aqui e o lado de lá é ali. O meio cheio de recheios. Cá e lá. [...] Procedências e desembocaduras (CUNHA, 1998, p. 21).

O lado de lá sem fronteiras. Os ganchos do lado de cá (CUNHA, 1998, p. 53).

Percebemos oposição também entre grupos tríplices, ou "tricotomias": passado x presente $x$ futuro, voz de eu $x$ voz de você x voz de ela, casa do pai $x$ apartamento do marido (2 quartos) $x$ apartamento dela (4 quartos), lembrança do namorado dos cabelos de mel que queria ser artista x existência do marido que usa dois relógios de pulso x amigo amante de barba grisalha marido da amiga loura.

Vejamos como Helena Parente Cunha constrói essa última relação de oposição tríplice, que não aponta para uma perspectiva dialética de tese, antítese e síntese, mas que se faz de três momentos/vivências as quais, opondo-se, são únicas e não passíveis de aproximação entre si, ainda que guardem vagas semelhanças:

Meu ver no ver do menino. Tangências. Meus olhos policromáveis e meu olhar de miragem. $O$ meu cabelo lilás. Meu sorriso de refluxos. Eu entre névoas e neblinas emanações e vapores. Eu tinha uma estrela vermelha na boca. E tremia estremecida entre favos de mel (CUNHA, 1998, p. 52).

Cindida ferir carne viva exposta. Você vê o devagar de seu marido repassando as fichas dos clientes. Visgo lentidões compactável. Eclipse do sol e das estrelas na noite concentrada de gritos empurrados no precipício. [...] Cicatrizes (CUNHA, 1998, p. 53).

Transposições e voar. [...] Ele passa a mão no seu cabelo castanho. Uma estrela refulge na sua boca entreaberta. [...] Você reconhece no beijo dele uma fulguração de doze estrelas recentes. Você submerge nos flocos de coral e nas emanações de tabaco e lavanda. Junto à fonte da cor da chuva você sente em seu corpo o pulsar das ondas represadas. 0 grande rio é um mar onde você mergulha sem medo (CUNHA, 1998, p. 79). 
E, se for possível, vemos ainda uma espécie de "tetratomia", confronto entre o grupo de quatro elementos: amiga loura $x$ amiga dos olhos verdes $x$ amiga dos cabelos cor de fogo $x$ amiga negra. Por exemplo:

A voz de certeza da amiga [...] A amiga não oferecendo dúvidas sobre o bem e o mal. Convicções resíduos camadas. A voz da exatidão [...] A voz da mulher loura abrangerá todas as vozes que se fecharão nos desenhos dos círculos em asfixia de 360 graus (CUNHA, 1998, p. 29).

Andrea do

Roccio Souto

122
Sua amiga jornalista vai ao seu apartamento. Os olhos verdes duas folhas de hortelã acesas. [...] Sua amiga fala nas experiências da vida amorosa de desquitada e nas facilidades da vida financeira. $\mathrm{E}$ fala de suas reportagens que questionam os mecanismos responsáveis pela opressão da mulher e denunciam as estruturas sociais-políticas-econômicas geradoras das milhares de prostitutas das cidades grandes. Bafejo de policromias novas e vermelhos inadiáveis e roxos imprevistos (CUNHA, 1998, p. 23).

A voz de sua amiga prostituta do outro lado. 0 outro lado do lado de lá (CUNHA, 1998, p. 69).

A mulher dos cabelos cor de fogo lhe abre os braços e as franjas das transposições. Além do lado de lá o cume estrelado da montanha. [...] Reflexos vermelhos impregnam a sala. [...] Doze labaredas refulgem nos cabelos cor de fogo. A verdade dos roxos sangrentos (CUNHA, 1998, p. 71).

Ela sempre será amiga da mulher negra e lhe deverá muitos fazeres. Ela verá o percurso da amiga negra que contém e abrange inclusões e dentro $\mathrm{E}$ receberá da amiga seu muito faz tantos fazeres de incessante flor. [...] Ela continuará a deitar a cabeça no colo da mulher negra para chorar caminhos e descaminhar primaveras e desflorescer. Ela continuará a ver atrás dos óculos irrestritos o olhar habituado a traspassar transcendências. [...] Na presença imune da amiga ela se sentirá segura porque nas mãos negras cabe o mundo com todas as suas cores de muitos vermelhos e roxos todos (CUNHA, 1998, p. 65). 
De qualquer forma, a narrativa, na medida em que constrói oposições, também as dilui, apontando um apagamento de contrastes que culmina na fragmentação dos próprios confrontos, o que remonta ao exercício da desconstrução "não só nas investidas contra as oposições binárias, mas em toda a construção discursiva" (CUNHA, 1997, p. 125).

É na instância do fenotexto também que se situa, conforme Farina, a leitura dos diversos códigos de que a obra se serve para significar e representar, dentro de uma perspectiva literária, geralmente aspectos multidisciplinares. Se definirmos um código narrativo mesclado a um identitário, por exemplo, poderemos dizer que as três vozes narrativas (eu-você-ela), contando a história de perspectivas tempo-espaço diferentes, apontam para uma fragmentação da identidade da protagonista: quem é ela, de que matéria de vida se fez, de que modo acaba sua vida? As vozes da mesma mulher respondem:

\footnotetext{
Eu tinha medo. As diagonais aos meus pés se traçavam. Eu ia eu fui eu fosse. [...] Flor de sangue em antecedente ruptura. [...] Você se precipita no vermelho. [...] Os olhos fechados. Fuga de miragens tangentes. Choque de imediatez e transcendência. Você ouve o barulho dos vidros infringidos? Vermelho e vermelhos. [...] Flor de sangue em simultânea ruptura. [...] Ela imergirá nos intensos ramos dos laranjais floridos e seu corpo se cobrirá de abelhas alvorecidas. Remanescida do mel da infância (CUNHA, 1998, p. 106-107).
}

Se estendermos esses códigos à história real, dadas as circunstâncias em que se encontrava o Brasil dos anos 1980, isto é, a anistia e a reabertura - época em que vieram a público as primeiras edições de $A$ mulher no espelho e As doze cores do vermelho -, a junção de ambos os códigos (narrativo e identitário), na perspectiva de voz triádica (temporal e espacialmente) pode indicar a existência de variadas/diferentes vozes que, no período da redemocratização pós-ditadura militar, buscavam redescobrir/reviver/reconformar/ reconsolidar a identidade nacional em um país colonial, tão esfacelada e encoberta quanto a identidade feminina, em uma sociedade patriarcal.

Outro elemento importante sobressai-se nesse código identitário é o fato de que as personagens não têm nomes, são identificadas por cores, classe, funções que desempenham: o pintor boliviano, a amiga lou- 
ra classificável e classificada, a amiga negra médica, a amiga jornalista dos olhos verdes, a amiga prostituta dos cabelos cor de fogo, o marido da pasta preta, o marido arquiteto marido da amiga loura, o marchand. Além disso, aponta para a identidade como um processo de esconde-mostra em que impera o busca-acha-perde:

Seus desejos mais procedentes. Você quer conhecer gente que conheça sua pintura. Conhecer mergulhando atravessando vertical e profundo. Mas você tem medo de mostrar você. Você

Andrea do

Roccio Souto

124

guarda teu você. Seus quadros empilhados (CUNHA, 1998, p. 32).

E se o invisível que você vê não estiver no visível que você mostra? Muito medo de mostrar seu você-é no você-vê (CUNHA, 1998, p. 39).

Podemos ainda definir um código numérico, já que o doze, repetido ao longo da narrativa de Parente Cunha, é o número das divisões espaço-temporais, característica que salta aos olhos quando lemos os 4 x 12 módulos de As doze cores do vermelho. Segundo Chevalier e Gheerbrant (1997, p. 348), doze é

[...] o produto dos quatro pontos cardeais pelos três planos do mundo [...] divide o céu [...] em 11 setores, os 12 signos do zodíaco [...] simboliza o universo no seu curso cíclico espaço-temporal [...] na sua complexidade interna [...] representa também a multiplicação dos quatro elementos, terra, água, ar, fogo pelos três princípios alquímicos (enxofre, sal, mercúrio) [...] na simbologia cristã [, a] combinação do quatro do mundo espacial e do três do tempo sagrado medindo a criação-recriação, dá o número doze, que é o do mundo acabado (CHEVALIER; GHEERBRANT, 1997, p. 348).

O ato de criação-recriação está simbolizado na narrativa de Helena Parente Cunha através dos seus doze pincéis, que ela guardará com um suspiro e um rápido tremor de mão, para mais tarde sacá-los como sua única arma, livrando-os e a si mesma do esquecimento limitado/opressor, com a finalidade de viver intensamente através de seus vermelhos multicores. Entretanto, definitivamente, isso não significa que ali seja retratado um mundo acabado; pelo contrário, aponta que o universo fe- 
minino constrói-se sempre a cada dia, um pouco de cada vez, pincelada a pincelada, na busca incessante da liberdade e da autonomia que a mulher, personificada pela protagonista, suas filhas e amigas, persegue no mundo moderno, em meio a uma sociedade dominadora e patriarcal.

Na simbologia, "doze que é três multiplicado por quatro significa o quadrado multiplicado pelo triângulo. É a raiz da esfera, é o algarismo da perfeição" (CHEVALIER; GHEERBRANT, 1997, p. 349). O interessante é que, apesar de doze ser o algarismo perfeito, não é a perfeição que emerge da estrutura narrativa, nem da história narrada, nem do processo de escrita com que nos deparamos. Poderíamos considerar um esboço de perfeição apenas o que a pintora chama de o canto noturno da cigarra estelar, pois só aqueles que conseguem ouvi-lo partilham dos momentos de êxtase da protagonista - mesmo que não se trate de uma Multiplicidadee plurissignificação felicidade completa e perfeita, e sim fragilmente fragmentada.

Ainda conforme o registro de Chevalier e Gheerbrant,

[...] para os dogons e os bambaras do Mali, os princípios contrários 4 e 3 (fêmea e macho), que estão na base de todas as coisas, podem associar-se de duas maneiras, uma estática, outra dinâmica, das quais dependem os valores do número 7 e do número 12. [...] 12 [...] é o símbolo do devenir humano e do desenvolvimento perpétuo do universo [...] no pensamento africano [...] 12 é o número da ação, e não princípio estático como é o sete [...]. Doze é, em definitivo, e sempre, o número de uma realização, de um ciclo concluído (CHEVALIER; GHEERBRANT, 1997, p. 349).

Embora afinado com a ação, com o devir, o doze parece criar a possibilidade de completude apenas no futuro da protagonista, quando “doze estrelas renovarão seu corpo" (CUNHA, 1998, p. 15), através das "doze badaladas da meia-noite ressoando nas incidências de luzes no meio do dia" (CUNHA, 1998, p. 27). Nesse caso, o ciclo só estaria concluído com sua morte, quando a protagonista pintora mergulha no vermelho (do semáforo e do sangue), passando de vez para o lado de lá, em busca de sua liberdade plena: aí a sua realização.

Um código cromático também pode ser percebido na narrativa de Helena Parente Cunha. Segundo o verbete cor (CHEVALIER; GHEERBRANT, 1997, p. 275-280), determinadas cores significam os elementos e o próprio espaço, como o vermelho significa o fogo e a dimensão hori- 
zontal (mais clara em direção ao oriente, mais escura a ocidente). Para os egípcios, vermelho era a cor maldita, a cor de tudo que é prejudicial, mas, em geral, é a cor do sangue, da vida, da paixão, do sentimento, do espírito, da sublimação, e, por ser oriunda do sol, a melhor das cores.

Ao tratar do verbete vermelho, dizem Chevalier e Gheerbrant (1997, p. 944-946) que essa cor significa transgressão - especialmente se relacionada às proibições sobre as pulsões sexuais, a libido, os instintos passionais -, ou, em perspectivas variadas, imortalidade, liberdade. Para os alquimistas, "pela obra em vermelho se opera a digestão, o amaAndrea do durecimento, a geração ou regeneração do homem ou da obra" (CHEVARoccio Souto LIER; GHEERBRANT, 1997, p. 946). Além disso, o vermelho, que pode ter um caráter fúnebre, é dado também como cor ambivalente:

O vermelho-claro, brilhante, centrífugo, é diurno, macho, tônico, incitando à ação, lançando como o sol seu brilho sobre todas as coisas, como uma força imensa e irredutível (KANC). 0 vermelho-escuro, bem ao contrário, é noturno, fêmea, secreto e, em última análise, centrípeto; representa não a expressão, mas o mistério da vida. Um seduz, encoraja, provoca [...]; o outro alerta, detém, incita à vigilância, e, no limite, inquieta. [...] Este vermelho centrípeto é a cor do fogo central do homem e da terra (CHEVALIER; GHEERBRANT, 1997, p. 946, grifos do autor).

É por isto que os vermelhos da protagonista atingem as raias do roxo, para mostrar sua "obra em vermelho" a um só tempo rebelde e liberta. E se o vermelho brilhante e o sol remontam ao macho, a protagonista quer o sol e o céu vermelhos femininamente - e pinta sua vida com as suas doze cores, experimentando nuança por nuança, revivendo as delícias de um amor pueril para viver o amor capaz de libertá-la na fase adulta, livrando-a dos códigos de honra e lei do lado de cá, a fim de descontruir uma simbologia tão tendenciosa:

O sol se acontecia no horizonte. O céu ficava vermelhos. [...] O sol ficava redondo. $O$ céu era mais vermelhos (CUNHA, 1998, p. 30).

Muitos olhos derramados nas tintas dos quadros quentes. Constelações e cardumes. Revoadas de abelhas nos laranjais em flor (CUNHA, 1998, p. 37). 
Emanações de tabaco e lavanda. Ela dirá de flores vermelhas e alamedas profundas e fontes de cor da chuva e cigarras de olhos verdes. Quatro arco-íris sem começo nem fim derramarão novas cores. [...] o céu vermelhos. Os olhos acesos de constelações e cardumes. Respiração pulsação estrelas peixes. Bocas. A gruta ensolarada. Corais (CUNHA, 1998, p. 45).

Como genotexto, ou leitura profunda de As doze cores do vermelho, apontamos, no módulo 9 (CUNHA, 1998, p. 31), o que diz ela, no ângulo 3: “Como atravessar as palavras nos nós das sílabas e da incerteza?", ou o que diz você, no ângulo 2: "Você quer saber a verdade dos dois lados. Por que você não consegue fazer a sua pintura do lado de cá?”, ou, ainda, o que diz Multiplicidadee plurissignificação o eu no ângulo 1 da narrativa: "Começo de finitudes. [...] Nuclearidade para fragmentações". o que a protagonista procura e persegue é a liberdade capaz de propiciar a sua vivência plena como mulher-sujeito-único de seu destino, numa sociedade, no mínimo, livre de preconceitos de gênero e raça.

Trazendo à tona a questão do fazer literário, ali travestido do fazer pictórico, e do descobrir-se feminino nas incertezas identitárias, nas finitudes humanas, nas fragmentações modernas, nas incertezas vividas e enfrentadas e nas realizações (ainda que incompletas/fugazes) - vezes sim, vezes não, em qualquer dos lados -, poderíamos dizer que Helena Parente Cunha faz-nos pensar também sobre o caráter da produção feminina, já que se trata de um Bildungsroman. E como a autora mesma afirma - não como romancista, mas como ensaísta da própria obra -, grande parte de sua produção narrativa trata da representação ficcional da sua "vivência na ordem falocrática, marcada a ferro e fogo [...] em tantas mulheres pela opressão asfixiante da distinção hierarquizante dos gêneros" (CUNHA, 1997, p. 114).

$\mathrm{Na}$ base do texto lírico que Helena Parente Cunha tece para desmanchar o discurso dominante/colonizador/patriarcal, está aquilo com que a protagonista (todas as mulheres) se depara $(\mathrm{m})$ na sua realidade: "Bifurcação. Percursos que se abrem na divergência dos rumos" (CUNHA, 1998, p. 45). Frente à dificuldade e às dúvidas, resta à mulher a coragem:

\footnotetext{
Ela afirmará à amiga dos olhos verdes que não vai mais querer ouvir as vozes que fecham seu livre caminhar. Ilimitado ir. [...] Um rio atravessará o fechado e levará suas águas a muitas fozes. Mas (CUNHA, 1998, p. 67).
} 
Aí está: a coragem da mulher tem que surgir "apesar de" - e imperar "apesar de". Este é o discurso engajado que subjaz à narrativa pós-moderna de Helena Parente Cunha. Ser mulher, hoje e sempre (desde um quando em que isso não era verbalizado, só era sentido), é ser "mas": conflitos e realizações, transcendências e questionamentos, incertezas e liberdades; sempre buscas, que às vezes se chocam entre $\mathrm{si}$, como atesta a trajetória da protagonista/pintora de As doze cores do vermelho.

Andrea do

Roccio Souto

\section{REFERÊNCIAS}

BARBOSA, Maria José Somerlate. Espaçamento como registro cultural na obra de Helena Parente Cunha. In: SHARPE, Peggy (Org.). Entre resistir e identificar-se: para uma teoria da prática da narrativa brasileira de autoria feminina. Florianópolis: Mulheres; Goiânia: UFG, 1997. p. 139-152.

CUNHA, Helena Parente. Hora de fogo: poemas em combustão. Rio de Janeiro: Letra Capital, 2017.

CUNHA, Helena Parente. Poemas para amiga e outros dizeres. Florianópolis: Mulheres, 2014.

CUNHA, Helena Parente. Impregnações na floresta: poemas amazônicos. Florianópolis: Mulheres, 2013.

CUNHA, Helena Parente. Mulher no espelho. 10. ed. Florianópolis: Mulheres, 2013.

CUNHA, Helena Parente. Violência simbólica e estratégias de dominação. Rio de Janeiro: Editora da Palavra/Programa de Pós-Graduação em Ciência da Literatura da Faculdade de Letras, 2011.

CUNHA, Helena Parente. Falas e falares. Florianópolis: Mulheres, 2011. 
CUNHA, Helena Parente. Quem conta um conto: estudos sobre contistas brasileiras estreantes nos anos 90 e 2000. Rio de Janeiro: Tempo Brasileiro, 2008.

CUNHA, Helena Parente. Caminhos de quando e além: diálogo com poemas de Fernando Pessoa. Rio de Janeiro: Tempo Brasileiro, 2007.

CUNHA, Helena Parente. Cantos e cantares. Rio de Janeiro: Tempo Brasileiro, 2005.

CUNHA, Helena Parente. Além do cânone: vozes femininas cariocas estreantes na poesia dos anos 90. Rio de Janeiro: Tempo Brasileiro, 2004.

CUNHA, Helena Parente. Marcelo e seus amigos invisíveis. São Paulo: Global, 2003.

CUNHA, Helena Parente. Claras manhãs de Barra Clara. Rio de Janeiro: Mondrian, 2002.

CUNHA, Helena Parente. Desafiando o cânone: aspectos da literatura de autoria feminina na prosa e na poesia (anos 70-80). Rio de Janeiro: Tempo Brasileiro, 1999.

CUNHA, Helena Parente. Vento Ventania Vendaval. Rio de Janeiro: Tempo Brasileiro, 1998.

CUNHA, Helena Parente. As doze cores do vermelho. 2. ed. Rio de Janeiro: Tempo Brasileiro, 1998.

CUNHA, Helena Parente. A mulher partida: a busca do verdadeiro rosto na miragem dos espelhos. In: SHARPE, Peggy (Org.). Entre resistir e identificar-se: para uma teoria da prática da narrativa brasileira de autoria feminina. Florianópolis: Editora Mulheres; Goiânia: Editora da UFG, 1997. p. 107-137.

CUNHA, Helena Parente. A casa e as casas. Rio de Janeiro: Tempo Brasileiro, 1996. 
CUNHA, Helena Parente. 0 outro lado do dia: poemas de uma viagem ao Japão. Rio de Janeiro: Tempo Brasileiro, 1995.

CUNHA, Helena Parente. Mulheres inventadas: leitura psicanalítica de textos na voz masculina. Rio de Janeiro: Tempo Brasileiro, 1994.

CUNHA, Helena Parente. As doze cores do vermelho. Rio de Janeiro: Espaço e Tempo e Editora da Universidade Federal do Rio de Janeiro, 1989.

Andrea do

Roccio Souto

CUNHA, Helena Parente. Cem mentiras de verdade. Rio de Janeiro: José Olympio, 1985.

130

CUNHA, Helena Parente. Mulher no espelho. Florianópolis: Fundação Catarinense de Cultura, 1983.

FARINA, Sérgio. Estatuto poético: uma proposta metodológica de leitura analítica e interpretativa. São Leopoldo: Unisinos, 1996.

PESSOA, Fernando. Obra poética. Rio de Janeiro: Nova Aguilar, 1999.

SCHMIDT, Rita Terezinha. Para que crítica feminista? (Anotações para uma resposta possível). In: VI SEMINÁRIO NACIONAL SOBRE MULHER E LITERATURA, 1995, Rio de Janeiro. Anais... Rio de Janeiro: UFRJ, NIELM, 1996. p. 138-149.

SOUZA, Lynn Mario Menezes de. Identidade e subversão: o discurso crítico-literário pós-colonial de Homi Bhabha. In: IV CONGRESSO DA ABRALIC - LITERATURA E DIFERENÇA, 1994, São Paulo. Anais... São Paulo: Bartira, 1995. p. 561-565. 